\title{
KUALITAS PELAYANAN PASIEN RAWAT JALAN PESERTA BADAN PENYELENGGARA JAMINAN SOSIAL DI PUSKESMAS PITUMPANUA KABUPATEN WAJO
}

\author{
OUTPATIENT SERVICE QUALITY OF \\ SOCIAL INSURANCE ADMINISTRATION AGENCY \\ AT PUBLIC HEALTH CENTER PITUMPANUA OF WAJO DISTRICT
}

\author{
Bidya Marsi ${ }^{1}$ dan Irawaty Amir ${ }^{2}$ \\ ${ }^{1}$ Puskesmas Pitumpanua Kabupaten Wajo \\ e-mail: bidyamarsi@ymail.com \\ ${ }^{2}$ Sekolah Tinggi Administrasi - Lembaga Administrasi Negara Makassar \\ e-mail:ir4_4m1r@gmail.com
}

\begin{abstract}
Abstrak
Puskesmas sebagai fasilitas kesehatan tingkat pertama memberikan pelayanan kesehatan sehingga merupakan ujung tombak bagi pembangunan kesehatan di tingkat kecamatan dan pelayanan kesehatan baik pada masyarakat sehat maupun sakit, baik untuk pelayanan rawat jalan maupun rawat inap. Untuk itu kualitas pelayanan kesehatan menjadi hal penting dalam organisasi pelayanan kesehatan karena dapat meningkatkan efisiensi dan efektifitas pelayanan kesehatan, meningkatkan penerimaan masyarakat terhadap pelayanan kesehatan dan dapat melindungi penyelenggara pelayanan kesehatan dari kemungkinan timbulnya gugatan hukum. Untuk itu penelitian ini bertujuan untuk menganalisis kualitas pelayanan pasien pasien rawat jalan Peserta Badan Penyelenggara Jaminan Sosial di Puskesmas Pitumpanua Kabupaten Wajo. Metode yang digunakan adalah kuantitatif deskriptif. Teknik pengumpulan data menggunakan kuesioner, telaah dokumen dan wawancara. Populasi dalam penelitian ini adalah semua Pasien Rawat Jalan Peserta BPJS yang berkunjung pada bulan Maret sampai bulan Mei 2017, dengan jumlah sampel 147 orang dengan menggunakan purposive sampling dan data dianalisis dengan menggunakan tabel frekuensi. Hasil penelitian ini menunjukkan bahwa pelayanan pasien Pasien Rawat Jalan Peserta Badan Penyelenggara Jaminan Sosial di Puskesmas Pitumpanua Kabupaten Wajo berada pada peringkat berkualitas, baik dilihat dari dimensi persyaratan, prosedur, waktu pelayanan, kompetensi pelaksana, perilaku pelaksana, maklumat pelayanan, dan penanganan pengaduan, saran dan masukan. Dalam rangka peningkatan kualitas pelayanan maka ada beberapa hal yang disarankan dan masih memerlukan perhatian seperti kenyamanan ruang poliklinik, kecepatan waktu pelayanan di loket kartu, penjelasan mengenai informasi fungsi dan cara konsumsi obat pada pelayanan di ruang obat, keramahan pelayanan di ruang obat, informasi jenis pelayanan yang tersedia di tiap ruangan rawat jalan, dan menambah ketersediaan kotak saran di ruang rawat jalan.
\end{abstract}

Kata Kunci: Kualitas Pelayanan, Badan Penyelenggara Jaminan Sosial, Puskesmas. 


\begin{abstract}
Puskesmas as first-rate health facilities provide health services so that is the spearhead for health development at the sub-district level, health services for both healthy and sick people, both for outpatient and inpatient services. Therefore, the quality of health services is important in the organization of health services because it can improve the efficiency and effectiveness of health services, increase public acceptance of health services and can protect health service providers from possible legal claims. Therefore, this study aims to analyze the quality of patient service of outpatients participating Social Insurance Administrative Agency (BPJS) at Pitumpanua Health Center Wajo Regency. The method used is descriptive quantitative. Data collection techniques used questionnaires, document review and interviews. The populations in this study were all outpatients of BPJS members who visited from March to May 2017, with a sample size of 147 people using purposive sampling and data were analyzed using frequency tables. The results of this study indicate that the service of outpatients participating Social Insurance Administrative Agency at Pitumpanua Health Center of Wajo Regency is in the rank of good quality, seen from the dimension of requirement, procedure, service time, executive competence, implementer behavior, service announcement, suggestions and inputs. However, to improve the quality of service then there are some things that are suggested and still require attention such as the convenience of the polyclinic unit, the speed of service time at the counter car

$d$, the explanation of the function information and the way of drug consumption on the service in the medicine room, information on the types of services available in each outpatient room, and to increase the availability of suggestion boxes in the outpatient room.
\end{abstract}

Keywords: Service Quality, Social Insurance Administrative Agency, Puskesmas.

\section{PENDAHULUAN}

Puskesmas sebagai fasilitas kesehatan tingkat pertama memberikan pelayanan kesehatan baik pada masyarakat sehat maupun sakit. Ia merupakan ujung tombak bagi pembangunan kesehatan di tingkat kecamatan. Puskesmas memberikan pelayanan imunisasi, promosi kesehatan, perbaikan gizi keluarga, pencegahan penyakit dan lainnya dalam upaya peningkatan derajat kesehatan. Selain itu pelayanan pengobatan juga diberikan bagi masyarakat yang sakit.

Pemerintah terus berupaya meningkatkan kualitas pelayanan kesehatan kepada masyarakat, salah satu cara pemerintah adalah melalui Departemen Kesehatan RI melalui penugasan kepada PT Askes (Persero) berdasarkan SK Nomor 1241/MENKES/ SK/XI/2004 dan Nomor 56/MENKES/SK/ I/2005, sebagai penyelenggara Program Jaminan Kesehatan Masyarakat Miskin
(PJKMM). Setelah beberapa tahun berjalan, pada tahun 2014 mulai tanggal 1 Januari PT Askes berubah nama menjadi Badan Penyelenggara Jaminan Sosial (BPJS) Kesehatan sesuai dengan Undang-Undang Nomor 24 Tahun 2011 Tentang BPJS Kesehatan. BPJS sebagai badan yang mengelola program Jaminan Kesehatan Nasional (JKN) (Herlambang, 2016).

Jumlah peserta BPJS diwilayah kerja Puskesmas Pitumpanua tertinggi di kabupaten wajo tahun 2015 sebanyak 15.116 jiwa, dan tahun 2016 sebanyak 18.325 jiwa. Sementara kunjungan rawat jalan di Puskesmas Pitumpanua rata-rata sebanyak 1.139 pasien setiap bulan. Sementara dokter yang bertugas hanya satu orang. Data ini menunjukkan bahwa Dokter menangani rata-rata 50 sampai 70 Pasien Rawat Jalan perhari ditambah dengan Pasien Rawat Inap. Untuk kondisi tertentu jika dokter berhalangan hadir maka penanganan pasien 
dilimpahkan ke Perawat atau Bidan. Hal ini tidak sesuai dengan peraturan yang berlaku bahwa pemberian diagnosa dan pengobatan hanya dilakukan oleh Dokter. Selain hal tersebut di atas, tenaga administrasi untuk pelayanan loket kartu masih kurang sehingga terkadang ada penumpukan pasien diloket kartu. Hal lain yang menjadi masalah dalam pelayanan di ruang rawat jalan adalah ketersedian obat yang masih terbatas dari dinas kesehatan, oleh karena itu penelitian ini bertujuan untuk menganalisis kualitas pelayanan Pasien Rawat Jalan Peserta Badan Penyelenggara Jaminan Sosial di Puskesmas Pitumpanua Kabupaten Wajo.

\section{METODE PENELITIAN}

\section{Tipe Penelitian}

Penelitian ini menggunakan metode penelitian kuantitatif deskriptif untuk mengetahui mengetahui persepsi peserta BPJS terhadap kualitas pelayanan rawat jalan di Puskesmas Pitumpanua.

\section{Populasi dan Sampel}

Populasi dalam penelitian ini adalah seluruh Pasien Rawat Jalan Peserta BPJS yang berkunjung di UPTD Puskesmas Pitumpanua selama bulan Maret sampai dengan April 2017 sebanyak 1.610 pasien, dengan jumlah sampel 147 orang dengan menggunakan purposive sampling, yang ditarik dengan menggunakan kriteria tertentu yaitu minimal dua kali kunjungan, berumur 17 sampai 50 tahun, dan pendidikan minimal SMA dan data dianalisis dengan menggunakan tabel frekuensi.

\section{Teknik dan Instrumen Pengumpulan Data}

Teknik dan instrumen pengumpulan data terdiri dari kuesioner, wawancara, dan telaah dokumen.

\section{Teknik Pengolahan dan Analisis Data}

Teknik pengolahan data yang dilakukan dalam penelitian ini adalah tabulasi data dengan analisis data menggunakan skala likert.

\section{HASIL PENELITIAN}

\section{Karakteristik Responden}

Karakteristik dalam penelitian ini meliputi; jenis kelamin, umur, tingkat pendidikan, pekerjaan responden, dan status kepesertaan responden. Data proporsi responden berdasarkan jenis kelamin adalah didominasi oleh perempuan, yakni sebanyak 111 responden atau sebanyak 75,51\%, jika dibandingkan dengan laki-laki sebanyak 36 responden atau $24,49 \%$.

Proporsi responden berdasarkan kelompok umur yang mendominasi responden adalah kelompok umur antara 31 tahun sampai 40 tahun yaitu sebanyak 48 responden atau 32,65 \%. Sementara responden dengan jumlah paling sedikit adalah kelompok umur kurang 20 tahun yaitu sebanyak 9 responden atau 6,12\%. Hal ini menunjukkan bahwa responden yang memberi pernyataan tentang kualitas pelayanan rawat jalan pada saat penelitian didominasi oleh kelompok umur 31 tahun sampai 40 tahun.

Proporsi responden berdasarkan status kepesertaan menunjukkan bahwa saat penelitian kelompok yang mendominasi responden adalah kelompok dengan status kepesertaan BPJS Penerima Bantuan Iuran (PBI) yaitu sebanyak 63 responden atau 42,86\%. Sementara responden dengan jumlah paling sedikit adalah kelompok dengan status kepesertaan ASKES yaitu sebanyak 30 responden atau 20,41\%. Hal ini menunjukkan bahwa responden yang memberi pernyataan tentang kualitas pelayanan rawat jalan pada saat penelitian didominasi oleh kelompok dengan status kepesertaan Penerima Bantuan Iuran (PBI).

Kualitas Pelayanan Pasien Rawat Jalan Peserta Badan Penyelenggara Jaminan Sosial

Kualitas pelayanan Pasien Rawat Jalan Peserta Badan Penyelenggara 
Jaminan Sosial di Puskesmas Pitumpanua Kabupaten Wajo dalam penelitian ini ditinjau dari dimensi persyaratan, prosedur, waktu pelayanan, kompetensi pelaksana, perilaku pelaksana, maklumat pelayanan, dan penanganan pegaduan, saran dan masukan.

\section{Dimensi Persyaratan}

Dimensi persyaratan yang diamati adalah berupa beberapa syarat wajib dan syarat pendukung yang dibutuhkan oleh organisasi pelayanan kesehatan dalam memberikan pelayanan, seperti kemudahan persyaratan administrasi rawat jalan, kejelasan persyaratan rawat jalan, kondisi tempat duduk di ruang tunggu, kenyamanan ruang tunggu, kenyamanan ruang poliklinik, ketersediaan obat di kamar obat, kenyamanan ruang laboratorium dan kenya-manan ruang tunggu kamar obat. Adapun hasil penelitian dapat dilihat pada Tabel 1.

Berdasarkan Tabel 1, hasil penelitian ini menunjukkan bahwa persyaratan merupakan salah satu dimensi yang berkualitas di ruang rawat jalan puskesmas Pitumpanua, tetapi hal yang masih perlu mendapat perhatian pelaksana pelayanan yaitu fasilitas pelayanan rawat jalan terutama kenyamanan dan kebersihan ruangan.

\section{Dimensi Prosedur Pelayanan}

Dimensi prosedur yang diamati adalah berupa cara dan sistematika yang harus
Tabel 1

Rekapan Tanggapan Responden Mengenai Kualitas Pelayanan Rerst Jan Peserta BPJS Ditinjau Dari Dimensi Persyaran

\begin{tabular}{|l|l|c|c|}
\hline No & Indikator Variabel & $\begin{array}{c}\text { Rata - rata } \\
\text { skor akhir }\end{array}$ & $\begin{array}{c}\text { Peringkat } \\
\text { kualitas }\end{array}$ \\
\hline 1. & $\begin{array}{l}\text { Kemudahan persyaratan administrasi } \\
\text { rawat jalan }\end{array}$ & 3,45 & 4 \\
\hline 2. & Kejelasan persyaratan rawat jalan & 3,20 & 5 \\
\hline 3. & Kondisi tempat duduk di ruang tunggu & 3,65 & 1 \\
\hline 4. & Kenyamanan ruang tunggu & 3,56 & 2 \\
\hline 5. & Kenyamanan ruang poliklinik & 3,00 & 7 \\
\hline 6. & Ketersediaan obat di kamar obat & 3,54 & 3 \\
\hline 7. & Kenyamanan ruang laboratorium & 3,16 & 6 \\
\hline 8. & Kenyamanan ruang tunggu kamar obat & 3,56 & 2 \\
\hline Jumlah & 26,30 & $\begin{array}{c}\text { Kategori } \\
\text { Berkualitas }\end{array}$ \\
\hline Rata-rata & 3,29 & \multicolumn{2}{|c}{} \\
\hline
\end{tabular}

dilalui dalam memberikan pelayanan, seperti kejelasan informasi alur pelayanan, kejelasan prosedur rawat jalan dari petugas, kejelasan informasi prosedur pelayanan di ruang poliklinik, kesesuaian pelayanan rawat jalan dengan prosedur di poliklinik, kemudahan pelayanan di poliklinik, kejelasan informasi prosedur pengambilan obat, kesesuaian prosedur pelayanan di kamar obat, kemudahan prosedur pelayanan di kamar obat. Adapun hasil penelitian dapat dilihat pada Tabel 2.

Tabel 2

Rekapan Tanggapan Responden Mengenai Kualitas Pelayanan Pasien Rawat Jalan Peserta BPJS Ditinjau Dari Dimensi Prosedur

\begin{tabular}{|l|l|c|c|}
\hline No & Indikator Variabel & $\begin{array}{c}\text { Rata - rata } \\
\text { skor akhir }\end{array}$ & $\begin{array}{c}\text { Peringkat } \\
\text { kualitas }\end{array}$ \\
\hline 1. & Kejelasan informasi alur pelayanan & 3,40 & 2 \\
\hline 2. & $\begin{array}{l}\text { Kejelasan prosedur rawat jalan dari } \\
\text { petugas }\end{array}$ & 3,37 & 4 \\
\hline 3. & $\begin{array}{l}\text { Kejelasan informasi prosedur di } \\
\text { ruang poliklinik }\end{array}$ & 3,39 & 3 \\
\hline 4. & $\begin{array}{l}\text { Kesesuaian pelayanan dengan prosedur } \\
\text { di poliklinik }\end{array}$ & 3,05 & 8 \\
\hline 5. & Kemudahan pelayanan di poliklinik & 3,27 & 6 \\
\hline 6. & $\begin{array}{l}\text { Kejelasan informasi prosedur } \\
\text { pengambilan obat }\end{array}$ & 3,30 & 5 \\
\cline { 1 - 2 } 7. & $\begin{array}{l}\text { Kesesuaian prosedur pelayanan } \\
\text { di kamar obat }\end{array}$ & 3,46 & 1 \\
\cline { 1 - 2 } 8. & $\begin{array}{l}\text { Kemudahan prosedur pelayanan } \\
\text { di kamar obat }\end{array}$ & 3,14 & 7 \\
\cline { 1 - 2 } Jumlah & 26,30 & $\begin{array}{c}\text { Kategori } \\
\text { Rata-rata }\end{array}$ \\
\hline
\end{tabular}

Sumber: Hasil Olahan Data Primer 2017 
Hasil penelitian ini menunjukkan bahwa prosedur merupakan salah satu dimensi yang berkualitas di ruang rawat jalan puskesmas Pitumpanua, tetapi hal yang masih perlu mendapat perhatian pelaksana pelayanan yaitu prosedur pelayanan terutama di ruang poliklinik dan di kamar obat.

\section{Dimensi Waktu Pelayanan}

Dimensi waktu pelayanan yang diamati adalah berupa kecepatan dan ketepatan waktu yang digunakan dalam memberikan pelayanan, seperti kejelasan waktu pelayanan, kesesuaian waktu pelayanan, kecepatan waktu pelayanan di loket kartu, ketepatan waktu pelayanan di

Tabel 3

Rekapan Tanggapan Responden Mengenai Kualitas Pelayanan Pasien Rawat Jalan Peserta BPJS Ditinjau Dari Dimensi Waktu Pelayanan

\begin{tabular}{|l|l|c|c|}
\hline No & \multicolumn{1}{|c|}{ Indikator Variabel } & $\begin{array}{c}\text { Rata - rata } \\
\text { skor akhir }\end{array}$ & $\begin{array}{c}\text { Peringkat } \\
\text { kualitas }\end{array}$ \\
\hline 1. & Kejelasan waktu pelayanan & 3,59 & 3 \\
\hline 2. & Kesesuaian waktu pelayanan & 3,35 & 6 \\
\hline 3. & $\begin{array}{l}\text { Kecepatan waktu pelayanan } \\
\text { di loket kartu }\end{array}$ & 3,09 & 8 \\
\hline 4. & $\begin{array}{l}\text { Ketepatan waktu pelayanan } \\
\text { di poliklinik }\end{array}$ & 3,65 & 2 \\
\hline 5. & $\begin{array}{l}\text { Kecepatan waktu pelayanan } \\
\text { di poliklinik }\end{array}$ & 3,32 & 7 \\
\hline 6. & $\begin{array}{l}\text { Kecepatan waktu pelayanan } \\
\text { di laboratorium }\end{array}$ & 3,69 & 1 \\
\hline 7. & $\begin{array}{l}\text { Kesesuaian waktu pelayanan } \\
\text { di ruang obat }\end{array}$ & 3,42 & 5 \\
\hline 8. & $\begin{array}{l}\text { Kecepatan waktu pelayanan } \\
\text { di kamar obat }\end{array}$ & 3,53 & 4 \\
\hline Jumlah & 27,63 & Kategori \\
\hline Rata-rata & 3,45 & Berkualitas \\
\hline
\end{tabular}

Sumber: Hasil Olahan Data Primer 2017 poliklinik, kecepatan waktu pelayanan di poliklinik, kecepatan waktu pelayanan di laboratorium, kesesuaian waktu pelayanan di ruang obat, kecepatan waktu pelayanan di kamar obat. Adapun hasil penelitian dapat dilihat pada Tabel 3.

Hasil penelitian ini menunjukkan bahwa waktu pelayanan merupakan salah satu dimensi yang berkualitas di ruang rawat jalan puskesmas Pitumpanua, tetapi hal yang masih perlu mendapat perhatian pelaksana pelayanan yaitu kualitas waktu pelayanan terutama kecepatan pelayanan di loket kartu.

\section{Dimensi Kompetensi Pelaksana}

Dimensi kompetensi pelaksana yang diamati adalah berupa kemampuan pelaksana untuk memberikan pelayanan kesehatan dengan baik, seperti kemampuan petugas berinteraksi dengan pasien, kemampuan menjelaskan tindakan yang akan dilakukan, kemampuan dokter menjelaskan penyakit pasien, kemampuan petugas menjelaskan fungsi obat, keterampilan petugas di loket kartu, keterampilan perawat melakukan tindakan keperawatan, keterampilan dokter memberikan pengobatan, dan keterampilan petugas dalam menyiapkan obat. Adapun hasil penelitian dapat dilihat pada Tabel 4 .

\section{Tabel 4}

Rekapan Tanggapan Responden Mengenai Kualitas Pelayanan Pasien Rawat Jalan Peserta BPJS Ditinjau Dari Dimensi Kompetensi Pelaksana

\begin{tabular}{|c|c|c|c|}
\hline No & Indikator Variabel & $\begin{array}{l}\text { Rata - rata } \\
\text { skor akhir }\end{array}$ & $\begin{array}{l}\text { Peringkat } \\
\text { kualitas }\end{array}$ \\
\hline 1. & $\begin{array}{l}\text { Kemampuan petugas berintraksi } \\
\text { dengan pasien }\end{array}$ & 3,65 & 1 \\
\hline 2. & $\begin{array}{l}\text { Kemampuan menjelaskan tindakan } \\
\text { yang akan dilakukan }\end{array}$ & 3,36 & 6 \\
\hline 3. & $\begin{array}{l}\text { Kemampuan dokter menjelaskan } \\
\text { penyakit pasien }\end{array}$ & 3,44 & 4 \\
\hline 4. & $\begin{array}{l}\text { Kemampuan petugas menjelaskan } \\
\text { fungsi obat }\end{array}$ & 3,17 & 8 \\
\hline 5. & Keterampilan petugas diloket kartu & 3,45 & 3 \\
\hline 6. & $\begin{array}{l}\text { Keterampilan perawat melakukan } \\
\text { tindakan keperawatan }\end{array}$ & 3,41 & 5 \\
\hline 7. & $\begin{array}{l}\text { Keterampilan dokter memberikan } \\
\text { pengobatan }\end{array}$ & 3,52 & 2 \\
\hline 8. & $\begin{array}{l}\text { Keterampilan petugas dalam } \\
\text { menyiapkan obat }\end{array}$ & 3,34 & 7 \\
\hline \multicolumn{2}{|r|}{ Jumlah } & 27,34 & Kategori \\
\hline \multicolumn{2}{|c|}{ Rata-rata } & 3,42 & Berkualitas \\
\hline
\end{tabular}

Sumber: Hasil Olahan Data Primer 2017 
Hasil penelitian ini menunjukkan bahwa kompetensi pelaksana merupakan salah satu dimensi yang berkualitas di ruang rawat jalan puskesmas Pitumpanua, tetapi hal yang masih perlu mendapat perhatian pelaksana pelayanan yaitu kualitas kompetensi petugas terutama di kamar obat.

\section{Dimensi Perilaku Pelaksana}

Dimensi perilaku pelaksana yang diamati adalah berupa tingkah laku pelaksana untuk memberikan pelayanan kesehatan, seperti keramahan petugas kamar kartu, kesabaran petugas kamar kartu, keadilan petugas kamar kartu, keramahan perawat dan dokter, kesabaran perawat dan dokter, keramahan petugas kamar obat, kesabaran petugas kamar obat, dan keadilan petugas kamar obat. Adapun hasil penelitian dapat dilihat pada Tabel 5 .

Hasil penelitian ini menunjukkan bahwa perilaku pelaksana merupakan salah satu dimensi yang berkualitas di ruang rawat jalan puskesmas Pitumpanua, tetapi yang masih perlu mendapat perhatian pelaksana pelayanan yaitu kualitas keramahan petugas terutama di kamar obat.

\section{Dimensi Maklumat Pelayanan}

Dimensi maklumat pelayanan yang diamati adalah pengumumanpengumuman untuk menginformasikan hal-hal yang berhubungan dengan pelayanan, seperti kejelasan visi, misi, dan motto puskesmas, kejelasan
Tabel 5

ekapan Tanggapan Responden Mengenai Kualitas Pelayanan Pasien Rawat Jalan Peserta BPJS Ditinjau Dari Dimensi Perilaku Pelaksana

\begin{tabular}{|l|l|c|c|}
\hline No & $\begin{array}{l}\text { Indikator Variabel } \\
\text { skor akhir }\end{array}$ & $\begin{array}{c}\text { Rata-rata } \\
\text { kualitas }\end{array}$ & Peringkat \\
\hline 1. & Keramahan petugas kamar kartu & 3,10 & 7 \\
\hline 2. & Kesabaran petugas kamar kartu & 3,32 & 6 \\
\hline 3. & Keadilan petugas kamar kartu & 3,49 & 2 \\
\hline 4. & Keramahan perawat dan dokter & 3,50 & 1 \\
\hline 5. & Kesabaran perawat dan dokter & 3,38 & 3 \\
\hline 6. & Keramahan petugas kamar obat & 3,07 & 8 \\
\hline 7. & Kesabaran petugas kamar obat & 3,33 & 5 \\
\hline 8. & Keadilan petugas kamar obat & 3,35 & 4 \\
\hline Jumlah & 26,54 & Kategori \\
\hline Rata-rata & 3,32 & Berkualitas \\
\hline
\end{tabular}

informasi tentang jenis pelayanan, kesesuaian pelayanan yang diberikan dengan visi, misi, dan motto puskesmas, dan kesesuaian pelayanan yang yang diberikan dengan jenis pelayanan. Adapun hasil penelitian dapat dilihat pada Tabel 6 .

Tabel 6

Rekapan Tanggapan Responden Mengenai Kualitas Pelayanan Pasien Rawat Jalan Peserta BPJS Ditinjau Dari Dimensi Maklumat Pelayanan

\begin{tabular}{|l|l|c|c|}
\hline No & \multicolumn{1}{|c|}{ Indikator Variabel } & $\begin{array}{c}\text { Rata - rata } \\
\text { skor akhir }\end{array}$ & $\begin{array}{c}\text { Peringkat } \\
\text { kualitas }\end{array}$ \\
\hline 1. & $\begin{array}{l}\text { Kejelasan informasi visi, misi, dan } \\
\text { motto puskesmas }\end{array}$ & 3,41 & 3 \\
\hline 2. & $\begin{array}{l}\text { Kejelasan informasi tentang } \\
\text { jenis pelayanan }\end{array}$ & 3,24 & 4 \\
\cline { 1 - 2 } 3. & $\begin{array}{l}\text { Kesesuaian pelayanan dengan visi, } \\
\text { misi, dan motto }\end{array}$ & 3,47 & 2 \\
\cline { 1 - 2 } 4. & $\begin{array}{l}\text { Kesesuaian pelayanan dengan } \\
\text { jenis pelayanan }\end{array}$ & 3,50 & 1 \\
\cline { 1 - 2 } Jumlah & 13,63 & $\begin{array}{c}\text { Kategori } \\
\text { Berkualitas }\end{array}$ \\
\hline \multicolumn{2}{|l|}{ Rata-rata } & 3,41 & \multicolumn{2}{|l}{} \\
\hline
\end{tabular}

Sumber: Hasil Olahan Data Primer 2017

Hasil penelitian ini menunjukkan bahwa maklumat pelayanan merupakan salah satu dimensi yang berkualitas di ruang rawat jalan puskesmas Pitumpanua, tetapi hal yang masih perlu mendapat perhatian pelaksana pelayanan yaitu kejelasan informasi tentang jenis pelayanan. 


\section{Dimensi Penanganan Pegaduan, Saran dan Masukan}

Dimensi penanganan, pengaduan, saran dan masukan yang diamati adalah berupa teknik yang dilakukan oleh organisasi kesehatan untuk menangani komplain dan saran dari masyarakat, seperti ketersediaan kotak saran, ketersediaan lembaran untuk pengajuan saran dan masukan, kesediaan petugas dalam mendengar keluhan pasien, ada respon dari setiap saran dan masukan, dan ada tindak lanjut dari saran dan masukan dari pelanggan. Adapun hasil penelitian dapat dilihat pada Tabel 7 .

Tabel 7

Rekapan Tanggapan Responden Mengenai Kualitas Pelayanan Pasien Rawat Jalan Peserta BPJS Ditinjau Dari Dimensi Penanganan Pegaduan, Saran dan Masukan

\begin{tabular}{|l|l|c|c|}
\hline No & Indikator Variabel & $\begin{array}{c}\text { Rata - rata } \\
\text { skor akhi }\end{array}$ & $\begin{array}{c}\text { Peringkat } \\
\text { kualitas }\end{array}$ \\
\hline 1. & Ketersediaan kotak saran & 3,06 & 5 \\
\hline 2. & $\begin{array}{l}\text { Ketersediaan lembaran untuk saran } \\
\text { dan masukan }\end{array}$ & 3,82 & 1 \\
\hline 3. & $\begin{array}{l}\text { Kesediaan petugas dalam mendengar } \\
\text { keluhan pasien }\end{array}$ & 3,28 & 4 \\
\hline 4. & $\begin{array}{l}\text { Ada respon dari setiap saran dan } \\
\text { masukan }\end{array}$ & 3,59 & 2 \\
\cline { 1 - 2 } 5. & $\begin{array}{l}\text { Ada tindak lanjut dari saran dan } \\
\text { masukan dari pelanggan }\end{array}$ & 3,46 & 3 \\
\cline { 1 - 2 } Jumlah & $\begin{array}{c}\text { Kategori } \\
\text { Berkualitas }\end{array}$ \\
\hline Rata-rata & &
\end{tabular}

Sumber: Hasil Olahan Data Primer 2017

Hasil penelitian ini menunjukkan bahwa penanganan, pengaduan, saran dan masukan merupakan salah satu dimensi yang berkualitas di ruang rawat jalan puskesmas Pitumpanua, tetapi hal yang masih perlu mendapat perhatian pelaksana pelayanan yaitu ketersediaan kotak saran.

\section{PEMBAHASAN}

Kualitas pelayanan merupakan hal penting dalam pelayanan termasuk pelayanan kesehatan dikarenakan menyangkut hidup dan matinya seseorang, selain itu kualitas pelayanan yang baik juga akan menarik Pasien untuk terus berkunjung sehingga dapat meningkatkan taraf hidup masyarakat setempat. Pelayanan kesehatan yang tidak berkualitas akan menyebabkan Pasien beralih ke fasilitas kesehatan lain, yang kemungkinan akan lebih memberatkan masyarakat dari segi biayanya.

Penelitian ini membahas kesehatan Puskesmas Pitumpanua Kabupaten Wajo dengan berdasarkan pengukuran dan dimensi kualitas pelayanan instansi pemerintah yang ditetapkan dalam Keputusan Menteri Pendayagunaan Aparatur Sipil Negara No 16 Tahun 2014, dari sembilan unsur yang ditetapkan, penelitian ini hanya meneliti tujuh dimensi saja, yaitu dimensi persyaratan, prosedur, waktu pelayanan, kempetensi pelaksana, perilaku pelaksana, maklumat pelayanan, dan penanganan pengaduan, saran dan masukan.

\section{Dimensi Persyaratan}

P e r s y a r a t a $n$ pelayanan yang jelas, mudah dan baik berpotensi memberikan kepuasan kepada pasien serta dapat mendorong Pasien untuk memanfaatkan lagi fasilitas rawat jalan pada Puskesmas Pitumpanua. Hal ini dapat dilihat dari akumulatif skor dari dimensi persyaratan berada pada kategori berkualitas dalam pelayanan rawat jalan di Puskesmas Pitumpanua Kabupaten Wajo.

Berdasarkan hasil penelitian maka penulis menyimpulkan bahwa untuk dimensi persyaratan yang paling berkualitas adalah kondisi tempat duduk diruang tunggu dimana hasil pengamatan kondisi tempat duduk dalam keadaan sangat baik dan sebagian masih baru. Hal ini dapat menjadi contoh bagi puskesmas lain dalam meningkatkan kualitas pelayanan. Di sisi lain kualitas kenyamanan ruang 
poliklinik masih mendapat skor terendah dimana hasil wawancara mengatakan bahwa, pada ruang poliklinik tidak tersedia sekat untuk ruang pemeriksaan pasien sehingga privasi pasien tidak terjaga. Hal ini bisa menjadi masukan bagi puskesmas untuk memperbaiki kualitas kenyamanan ruang poliklinik ke depan.

Hasil penelitian ini sejalan dengan penelitian yang dilakukan oleh Novita Ayu tahun 2016 di Puskesmas Segiri Kecamatan Samarinda Ulu, bahwa kualitas pelayanan peserta BPJS sudah cukup baik namun ditemukan berbagai hambatan diantaranya fasilitas ruang tunggu terbatas karena sempit, dan ketersediaan obat di puskesmas yang terbatas sehingga pelayanan tidak maksimal.

Hal ini sejalan dengan pernyataan Boediono (2003) bahwa penyelenggaraan pelayanan harus memiliki bentuk dan sifat kejelasan dan kepastian. Artinya kejelasan dan kepastian dalam hal yang berkaitan dengan prosedur atau tata cara pelayanan umum. Lebih lanjut Boediono mengatakan, perlu adanya efisiensi dalam hal persyaratan pelayanan umum, hanya dibatasi pada hal-hal yang berkaitan langsung dengan pencapaian sasaran pelayanan, dengan tetap memperhatikan keterpaduan antara persyaratan dengan produk pelayanan umum yang diberikan.

Pendapat lain tentang persyaratan di ungkapkan oleh Pohan (2007) bahwa kenyamanan juga terkait dengan penampilan fisik pelayanan kesehatan, pemberi pelayanan, peralatan medis dan non medis. Penampilan ruang tunggu yang baik dapat menimbulkan perasaan kenikmatan tersediri sehingga waktu tunggu tidak menjadi hal yang membosankan.

\section{Dimensi Prosedur}

Sesuai dengan hasil penelitian terhadap dimensi prosedur, dimana hasil penelitian ini menunjukkan sebagian besar responden memberikan tanggapan setuju dengan kejelasan, kemudahan, dan kesesuaian pelayanan dengan prosedur pelayanan yang diberikan. Kejelasan dan kemudahan prosedur pelayanan yang diberikan akan mendorong pasien untuk memanfaatkan kembali fasilitas rawat jalan di Puskesmas Pitumpanua. Hal ini dapat dilihat dari akumulasi skor dari dimensi prosedur sebesar 3,29 yang artinya berada pada kategori berkualitas pada pelayanan rawat jalan peserta BPJS di Puskesmas Pitumpanua kabupaten Wajo.

Untuk dimensi prosedur di Puskesmas Pitumpanua yang paling berkualitas adalah kesesuaian prosedur di kamar obat. Prosedur pelayanan di ruang obat sudah dilakukan sesuai dengan alur pelayanan yang pasang di dinding ruang tunggu, dan ini dapat dijadikan contoh bagi pelayanan kesehatan lainnya. Namun di sisi lain, masih ada variable dengan nilai yang rendah yaitu kesesuaian pelayanan rawat jalan dengan prosedur yang ada. Ketidak sesuaian prosedur di ruang poliklinik berdasarkan wawancara lebih banyak disebabakan karena pelayanan tidak dilakukan oleh Dokter melainkan Perawat. Di Puskesmas Pitumpanua hanya tersedia satu Dokter Umum sementara menurut Permenkes di puskesmas sebaiknya tersedia dua dokter. Keadaan ini dapat menurunkan kualitas pelayanan di Puskesmas, dan sebaiknya menjadi pertimbangan penentu kebijakan untuk mengambil tindakan perbaikan.

Menurut Boediono (2003), dengan adanya tata cara pelayanan yang jelas dan terbuka, maka masyarakat dalam pengurusan kepentingan dapat dengan mudah mengetahui prosedur ataupun tata cara pelayanan yang harus dilalui. Sehingga pelayanan itu sendiri akan memuaskan masyarakat.

\section{Dimensi Waktu Pelayanan}

Waktu pelayanan yang cepat akan menyelesaikan masalah dan keluhan pasien dengan mudah, hal ini akan 
menarik Pasien untuk datang berkunjung di Puskesmas dan mendapatkan pelayanan rawat jalan. Hasil penelitian menunjukkan bahwa pelayanan di loket kartu masih lama dan pasien masih harus menunggu lama untuk mendapatkan kartu dan buku rawat jalan. Oleh karena itu diharapkan pihak puskesmas mampu membuat inovasi untuk mempercepat pelayanan di loket kartu dan dapat mengurai antrian di loket kartu, agar Pasien tidak harus menunggu lama untuk mendapatkan pelayanan.

Situasi ini juga terjadi pada Tanggal 17 Oktober 2016 dimana terjadi penumpukan pasien BPJS di Puskesmas Petamburan. Hal ini mengakibatkan proses pelayanan di Puskesmas ini menjadi lambat dan tidak maksimal. Dokter hanya memberi pelayanan pada tiap pasien selama lima menit, hal ini memungkinkan pemeriksaan dokter tidak menyeluruh sehingga hasil diagnosis juga tidak maksimal. (Indopos, 2016)

Pada dimensi waktu pelayanan variabel dengan skor tertinggi adalah kecepatan waktu pelayanan di laboratorium. Sesuai dengan pernyataan Responden bahwa pelayanan di laboratorium sudah cepat, petugas selalu siap siaga untuk melayani Pasien setiap saat dan pada saat Pasien butuh pemeriksaan Petugas didapat langsung melayani. Keadaan ini dapat menjadi contoh bagi fasilitas pelayanan kesehatan lainnya dalam meningkatkan mutu pelayanan di laboratorium.

Hal ini sejalan dengan pendapat (Boediono, 2003), bahwa pelayanan oleh aparat pemerintah dengan mengulur waktu dengan berbagai alasan merupakan tindakan yang dapat mengecewakan masyarakat. Mereka yang membutuhkan secepat mungkin diselesaikan akan mengeluh jika tidak segera dilayani. Lagi pula jika mereka mengulur waktu, tentunya merupakan beban untuk tahap selanjutnya. Dengan mengulur waktu maka akan banyak tugas yang harus diselesaikan, hal ini bahkan akan merugikan pihak pemberi pelayanan itu sendiri.

\section{Kompetensi Pelayanan}

Kompetensi pelaksana yang handal dan profesional dapat meningkatkan kualitas pelayanan dengan memberi kepuasan pada Pasien akan pelayanan yang diberikan. Hal ini dapat mendorong Pasien untuk memanfaatkan lagi jasa pelayanan rawat jalan yang ada di Puskesmas Pitumpanua.

Berdasarkan hasil penelitian tentang kompetensi pelaksana, maka sebagian besar indikator sudah berkualitas, namun indikator kemampuan petugas dalam menjelaskan fungsi dan cara konsumsi obat mendapatkan skor 3,17, skor paling rendah dan menempati peringkat terakhir. Oleh karena itu dianjurkan untuk semua Petugas yang bertugas di kamar obat agar mampu menjelaskan kepada Pasien fungsi dan cara mengkonsumsi dari setiap obat yang diberikan pada Pasien.

Menurut Parasuraman (1990) bahwa salah satu penentu pelayanan sebagai dasar untuk memahami kualitas pelayanan yakni yang dibutuhkannya kompetensi yang merupakan ilmu pengetahuan dan keahlian yang dibutuhkan untuk memberi pelayanan sehingga dapat memberikan kepercayaan kepada pasien.

Pendapat lain yang sejalan dengan waktu pelayanan adalah menurut Sabaraguna (2004), kehandalan merupakan kemampuan perusahaan untuk memberikan pelayanan sesuai yang dijanjikan secara akurat dan terpercaya. Kinerja harus sesuai dengan harapan pelanggan yang berarti tepat waktu dalam pelayanan.

\section{Perilaku Pelaksana}

Perilaku pelaksana yang baik akan memudahkan membangun hubungan komunikasi antara Petugas dan Pasien, dimana dapat membantu Pasien untuk 
mengatasi masalah yang sedang dihadapi Pasien. Sesuai dengan hasil penelitian terhadap perilaku Pelaksana, maka sebagian besar Responden memberikan tanggapan setuju dengan kualitas Perilaku Pelaksana. Sementara variabel kemampuan Petugas Obat dalam menjelaskan fungsi dan cara konsumsi obat masih kurang berkualitas. Petugas di ruang rawat obat masih sering tidak memberikan informasi pada pasien tentang cara mengkonsunsumsi obat dan fungsi.

Menurut Lupiyoadi (2001) mengatakan dalam menghadapi pelanggan yang emosi atau marah, pemberi pelayanan perlu bersikap empathy, karena bila tidak maka situasi akan bertambah runyam. Untuk itu perlu diluangkan waktu untuk mendengar keluhan mereka dan berusaha memahami situasi yang dirasakan oleh pelanggan.

Menurut Moenir (2003), mengatakan bahwa; ada beberapa masalah pokok dari pelayanan yang diberikan kepada masyarakat, salah satunya adalah tingkah laku yang sopan dari petugas, cara penyampaian, dan keramahtamahan petugas.

Hasil penelitian Pardede (2016) di Puskesmas Kedung Mundu Kota Semarang, tentang ketanggapan yang diberikan kepada pasien di Puskesmas ini sudah baik. Kualitas pelayanan melalui dimensi jaminan yang diberikan kepada pasien sudah baik. Sementara untuk dimensi mutu perhatian yang diberikan kepada pasien juga sudah baik.

\section{Maklumat Pelayanan}

Maklumat pelayanan yang jelas dari pihak pemberi pelayanan kepada penerima pelayanan terutama tentang jenis- jenis pelayanan yang tersedia akan memudahkan pasien untuk menentukan jenis pelayanan yang akan diterima, hal ini akan menarik pasien untuk datang berobat dan mendapatkan pelayanan kesehatan di puskesmas.
Hasil penelitian dari dimensi maklumat pelayanan menunjukkan kualitas yang baik, namun indikator kejelasan informasi tentang jenis pelayanan yang tersedia mendapatkan skor 3,24, dan merupakan skor paling rendah dari dimensi ini.

Hal ini menunjukkan bahwa masih ada jenis pelayanan di Puskesmas Pitumpanua yang tidak diinformasikan dengan baik oleh pihak Petugas. Oleh karena itu diharapkan di setiap ruangan poliklinik terdapat informasi tentang jenis pelayanan yang tersedia, begitu juga Petugas sebaiknya menjelaskan jenisjenis pelayanan yang tersedia di tiap bagian rawat jalan bagi Peserta BPJS di Puskesmas Pitumpanua.

Variabel dengan skor tertinggi pada dimensi maklumat pelayanan di Puskesmas Pitumpanua adalah kesesuaian visi, misi, dan motto dengan pelayanan yang diberikan. Pelayanan merupakan cerminan dari tujuan puskesmas secara khusus. Setiap visi dan misi yang ada harus menjadi pedoman bagi karyawan dalam melaksanakan pelayanan, dan ini telah ditunjukkan oleh petugas di ruang rawat jalan.

Budianas (2013) menjelaskan bahwa sekalipun prinsip pokok program menjaga mutu pada pelayanan rawat jalan tidak banyak berbeda dengan berbagai pelayanan kesehatan lainnya, namun karena pada pelayanan rawat jalan ditemukan beberapa ciri khusus, menyebabkan penyelenggaraan program menjaga mutu pada pelayanan rawat jalan tidaklah semudah yang diperkirakan, ciriciri khusus yang dimaksud adalah:Sarana, prasarana serta jenis pelayanan rawat jalan sangat beraneka ragam, sehingga sulit merumuskan tolak ukur yang bersifat baku.

\section{Penanganan Pengaduan, Saran dan Masukan}

Penanganan pengaduan, saran dan masukan yang baik berpotensi membangun komunikasi yang baik 
antara Pasien dan Petugas, serta dapat memberi kepuasan bagi Pasien sehingga mendorong Pasien untuk memanfaatkan lagi fasilitas rawat jalan di Puskesmas. Sebagian besar indikator pada dimensi penanganan pengaduan, saran dan masukan sudah berkualitas baik, namun kesediaan kotak saran mendapatkan skor paling rendah yaitu 3,06 . Oleh karena itu dianjurkan agar petugas rawat jalan mampu meluangkan waktu untuk mendengarkan keluhan dari pasien yang berkunjung di ruang rawat jalan Puskesmas Pitumpanua.

Indikator dengan skor tertinggi pada dimensi ini adalah ketersediaan lembar pengaduan, saran dan masukan. Sebagaimana yang terlihat pada gambar 16 bahwa pada kotak saran tersedia lembar dan alat tulis untuk menuliskan saran. Ini dapat menjadi contoh yang baik bagi penyedia layanan dalam meningkatkan kualitas pelayanan. Setiap kotak saran harus dilengkapi dengan alat tulis menulis agar pelanggan dapat lebih nyaman dalam menyampaikan saran dan masukannya.

Menurut Kotler dan Keller (Algifari, 2016), salah satu cara untuk mengetahui kepuasan pelanggan adalah dengan system keluhan dan saran. Penyelenggara pelayanan sebaiknya menyediakan formulir yang akan diisi oleh pelanggan atau pengguna pelayanan untuk menyatakan hal-hal yang dirasakan oleh pelanggan memuaskan dan hal-hal yang tidak memuaskan. Pemberi layanan juga dapat menyediakan kotak saran atau telpon pengaduan bagi pelanggan yang merasa dirugikan. Informasi yang diperoleh dari kegiatan ini akan memberi manfaat bagi pemberi layanan untuk dapat segera menyelesaikan masalah.

Menurut Tjiptono (2004), bahwa kecepatan merupakan hal yang sangat penting dalam penanganan keluhan. Apabila keluhan pelanggan tidak segera ditanggapi, maka rasa tidak puas terhadap perusahaan akan menjadi permanen dan tidak dapat diubah lagi. Sedangkan apabila keluhan dapat ditangani dengan cepat, maka ada kemungkinan pelanggan tersebut puas.

\section{KESIMPULAN DAN SARAN}

Kami menyimpulkan bahwa kualitas pelayanan rawat jalan Peserta Badan Penyelenggara Jaminan Sosial (BPJS) di Puskesmas Pitumpanua termasuk kategori berkualitas. Namun demikian, untuk dapat menyempurnakan kualitas pelayanan maka kepala puskesmas perlu melakukan beberapa hal. Pertama, memperbaiki kenyamanan ruangan poliklinik, baik dari segi fasilitas ruangan seperti disediakan sekat untuk pemeriksaan agar privasi Pasien dapat terjaga maupun kebersihan di ruangan poliklinik. Kedua, mengadakan pengusulan ke Dinas Kesehatan untuk penambahan Tenaga Dokter, mengingat cuma tersedia satu dokter yang menangani semua Pasien di rawat jalan dan rawat inap. Hal ini menjadikan pelayanan rawat jalan terkadang dilakukan oleh perawat bukan dokter, sehingga pelayanan yang diberikan di poliklinik tidak sesuai dengan prosedur pelayanan. Ketiga, mempertimbangkan untuk menambah tenaga di ruang pengambilan kartu agar tidak terjadi penumpukan Pasien di ruang kartu dan pelayanan menjadi lama. Keempat, Petugas yang bekerja di ruang obat Puskesmas Pitumpanua, perlu memperbaiki kompetensi petugas dengan memperbaiki pelayanan di kamar obat dimana petugas harus menjelaskan fungsi dan cara konsumsi obat pada setiap Pasien agar tidak terjadi kesalahan dan meminimalkan efek samping obat pada Pasien. Kelima, Petugas Pelayanan Rawat Jalan terutama di ruang obat agar mampu bersikap lebih ramah saat menyapa pasien, dan saat melakukan pelayanan pada pasien yang berkunjung di Puskesmas Pitumpanua. Keenam, Petugas di tiap ruangan rawat jalan agar menyiapkan jenis pelayanan 
yang tersedia di tiap ruangan, agar Pasien dapat menerima pelayanan sesuai dengan kebutuhan dan masalah yang dihadapi. Ketujuh, Petugas di ruang rawat jalan seharusnya menambah kotak saran di ruang rawat jalan agar Pasien dapat lebih nyaman dalam menyampaikan keluhan atau saran bagi pelayanan di Puskesmas Pitumpanua.

\section{REFERENSI}

Algifari. 2016. Mengukur Kualitas Layanan. Yogyakarta: Fakultas Ekonomika dan Bisnis UGM.

Ayu. 2016. Pelayanan Badan Penyelenggara Jaminan Sosial Kesehatan di Puskesmas Segiri Kecamatan Samarinda Ulu. Makassar: Jurnal Administrasi Negara.

Boediono B. 2003. Pelayanan Prima Perpajakan. Jakarta: PT. Rineka Cipta.

Herlambang S. 2016. Manajemen Pelayanan Kesehatan Rumah Sakit. Yogyakarta: Gosyen Publishing
Lupiyoadi. 2001. Manajemen Pemasaran Jasa Teori dan Praktek. Jakarta: Penerbit Salemba.

Moenir H.A.S. 2003. Manajemen Pelayanan Umum di Indonesia. Jakarta: Bumi Aksara.

Parasuraman. 1990. Delivering Quality Service; Balancing Customer Percetions And Expectation. New York: Division of Macmillan.

Pardede. 2016. Analisis Perbedaan Persepsi Pasien Peserta BPJS terhadap Penilaian Mutu Pelayanan di Puskesmas Kedungmundu Kota Semarang Tahun 2016. Semarang: Jurnal Kesehatan Masyarakat.

Pohan Imbalo S. 2007. Jaminan Mutu Layanan Kesehatan. Jakarta: Penerbit Buku Kedokteran EGC.

Sabaraguna B S. 2004. Quality Assurance Pelayanan Rumah Sakit. Yogyakarta: Konsorsium Rumah Sakit Islam Jateng.

Tjiptono F. 2004. Kepuasan Dalam Pelayanan Prima. Jakarta: Penerbit Salemba. 